CASA, Vol.10 n.1, julho de 2012

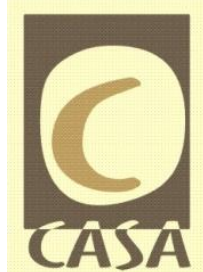

Cadernos de Semiótica Aplicada

Vol. 10.n.1, julho de 2012

Publicação SEMESTRAL

ISSN: $1679-3404$

\title{
O SINCRETISMO REVISTO SEGUNDO O CONCEITO DE MESTIÇAGEM DE ZILBERBERG
}

\section{THE NOTION OF SYNCRETISM REVISED BY THE ZILBERBERG'S CONCEPT OF MESTIZAJE}

\author{
Carolina Tomasi \\ USP - Universidade de São Paulo \\ $\mathrm{CNPq}$
}

RESUMO: Este artigo retoma os conceitos de sincretismo de Hjelmslev (1975), de Greimas e Courtés (1983) e de Floch (2007) e tem como objetivo uma breve reflexão a respeito dessa problemática teórica. Todavia, para refletir a teoria, não se pôde deixar de considerar a importância do texto de Zilberberg (2004) sobre a mestiçagem. Ao partir do pressuposto de que o sincretismo dá-se gradualmente, tensivamente e, com base na terminologia desse autor no estudo sobre a mestiçagem, que vai da triagem à mistura, da separação à fusão e do bizarro ao tédio, verificamos como o sincretismo, fusão nos termos zilberberguianos, permitiu-nos verificar que o texto verbo-visual do enunciado da capa de Território de bravos é um espaço tensivo em que contrários e contraditórios convocam-se ininterruptamente.

PALAVRAS-CHAVE: Semiótica tensiva; sincretismo; mestiçagem.

ABSTRACT: This article revisits the concept of syncretism of Hjelmslev (1975), Greimas, Courtés (1983) and Floch (2007) and aims at brief review of this theoretical problem. However, for a refinement of the theory, one cannot fail to consider the importance of the text of Zilberberg (2004) on miscegenation. By the assumption that the syncretism takes place gradually, in a succession de tensive positions, and based on the terminology of this author on the study of the mixture, which goes of the mix to screening, of separation to fusion, of the bizarre to boredom, we examine how the syncretism, merger pursuant of zilberberg, allowed us to verify that the space of utterance of Território de bravos is a tensive space in which contradictory and contrary notice is uninterrupted.

KEYWORDS: Tensive semiotics; syncretism; miscegenation.

\section{Introdução}

Este artigo, com base no conceito de mestiçagem de Zilberberg (2004. p. 69101), aborda o sincretismo, considerando como corpus a capa de um livro de um artista plástico, autor de histórias em quadrinhos (HQs). Essa capa nos chamou a atenção pela 
plasticidade, bem como por contemplar, no mesmo enunciado, categorias que vão da fusão à separação, nos termos zilberberguianos.

A capa de Território de bravos de Luiz Gê (ver anexo neste artigo), livro de HQs publicado em 1993 pela Editora 34, pode ser dividida em duas partes: superior e inferior. A capa é toda colorida, sobressaindo as cores amarela, azul, verde, laranja e vermelha. $\mathrm{Na}$ parte superior centralizada, há o texto verbal "Luiz Gê" (letra cursiva, simulando o enunciador) e, logo abaixo, os dizeres "TERRITÓRIO DE BRAVOS". No pé da capa, centralizado, há o texto verbal "Editora 34". Na parte superior da capa, há figuras, como o céu em tons amarelados e avermelhados, um cavaleiro e um cavalo em movimento, bem como a poeira levantada pelo movimento do cavalo. Na parte inferior da capa, as figuras discursivas representam, de forma tensiva (e ambígua), automóveis parados e desalinhados (simulando um engarrafamento), com passageiros no seu interior. Edifícios antigos e novos são outras figuras discursivas que também participam do espaço enunciado: céu, edifícios, um viaduto, chão em que cavalga um cavaleiro, um cavalo, poeira, automóveis, pessoas, espaço aberto, espaço fechado. Esses elementos formam duas isotopias: a de uma cidade dos primórdios de sua fundação e a de uma cidade atual, que tematizam a antiguidade e a modernidade da cidade de São Paulo. ${ }^{1}$

Como veremos a seguir, o conceito de sincretismo pode ser abordado juntamente com o conceito de direção, para o qual as grandezas aproximação e afastamento se opõem. Além disso, contamos com o conceito de intimidade que, de acordo com Hjelmslev (1999), confronta a aderência (o contato) e a inerência.

\section{Breve retomada dos conceitos de sincretismo}

Retomando o conceito de Greimas e Courtés (1983. p. 426), sincretismo é o procedimento ou resultado "que consiste em estabelecer, por superposição, uma relação entre dois (ou vários) termos ou categorias heterogêneas, cobrindo-os com o auxílio de uma grandeza semiótica (ou linguística) que os reúne”. Para esses autores, são consideradas sincréticas "as semióticas que [...] acionam várias linguagens de manifestação". São, portanto, apresentados por eles dois conceitos, um de sincretismo, apoiado na definição 78 de Hjelmslev (1975. p. 140), "sincretismo: categoria estabelecida por superposição", e outro de semióticas sincréticas.

Floch (2007, p. 319-320) afirma que as semióticas sincréticas caracterizam-se pelo emprego de diversas linguagens de manifestação. Seriam uma estratégia da enunciação, utilizada apenas como um mecanismo enunciativo. Nesse caso, podemos dizer que tanto nas histórias em quadrinhos como no cinema, há uma semiótica sincrética. Dessa forma, para ele, não há, em um enunciado sincrético, uma enunciação visual e outra verbal. Se houvesse duas enunciações, o enunciatário teria hipoteticamente de entrar mais de uma vez no cinema para apreender uma enunciação de cada vez: uma para a apreensão do verbal, outra para a do visual.

Fiorin (2009. p. 30-31) esclarece que melhor que falar em semiótica sincrética é referir-se a texto sincrético, em que a enunciação utiliza diferentes substâncias para manifestar, no texto, um conteúdo e uma forma de expressão. Caberia então, segundo o autor, uma investigação da enunciação sincrética.

Afirma ainda o linguista, com base em Hjelmslev, que o sincretismo é "uma fusão". Sua manifestação é "idêntica à manifestação de todos os funtivos que nele entram". E

\footnotetext{
${ }^{1}$ Sabemos que se trata da cidade de São Paulo por informações constantes dos enunciados presentes no interior do livro.
}

Disponível em: http://seer.fclar.unesp.br/casa 
acrescenta que "a manifestação do sincretismo ocorre no mesmo nível em que estão os funtivos em superposição" (FIORIN, 2009). E apresenta como exemplo a superposição dos funtivos tempo e espaço que entram em sincretismo (fusão): "Quando se diz uma hora para responder à questão Campinas está a quantos quilômetros de São Paulo?”

Centralizamos nossas preocupações, todavia, no conceito de sincretismo apenas como categoria estabelecida por superposição, pois essa reflexão nos aproximará do conceito zilberberguiano de mestiçagem. Essa categoria seria capaz de iluminar determinados objetos semióticos, como a capa em estudo. Não nos interessa, no momento, discutir questões relativas à edição e à montagem da capa, que estão diretamente relacionadas à enunciação sincrética, uma questão de estratégia de produção do sentido na junção das linguagens (verbovisual, por exemplo). Ocupamo-nos apenas da breve análise de elementos que se fundem no enunciado, uma forma de sincretismo, reconhecendo porém que a enunciação é a ele pressuposta.

\section{Sincretismo do enunciado da capa}

Vejamos, a seguir, a capa de Luiz Gê, corpus da análise neste artigo:

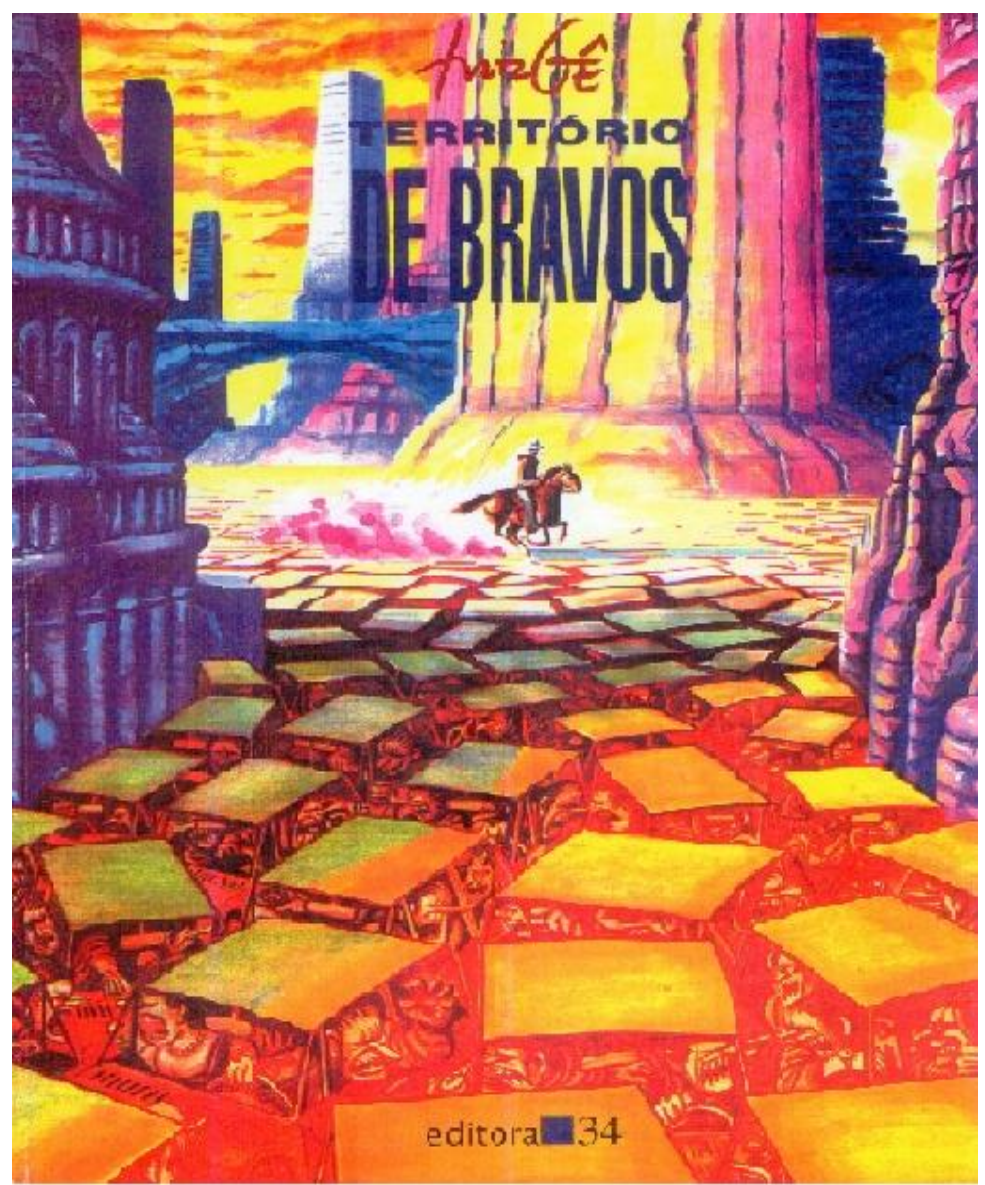

Figura 1: capa de Luiz Ge

Notamos a superposição dos funtivos espaço e tempo, ou, noutros termos, o espaço funde-se com o tempo de tal forma que o enunciatário percebe o espaço antigo como progressão temporal que leva à percepção de um tempo moderno. O espaço funde-se 
gradualmente com o tempo. Trata-se, portanto, de um enunciado sincrético, segundo o conceito de Zilberberg.

Observemos inicialmente as escolhas tensivas que orientam o sincretismo do enunciado da capa, segundo Zilberberg (2004. p. 73-85):

1. a direção, segundo a qual se opõem aproximação e afastamento entre duas grandezas;

2. a definição de amálgama e liga;

3. a constituição do sentido que estaria situada na junção entre uma medida intensiva e um número extensivo;

4. o processo da triagem à mistura em que temos, ao mesmo tempo, uma difusão extensiva e uma diluição intensiva.

Dada a classe $X,{ }^{2}$ uma grandeza $Y$ penetra em sua vizinhança e faz surgir uma tensão. Voltemos os olhos para a capa acima: grandeza X: chão do cavaleiro; grandeza Y: tetos dos automóveis. Afastam-se no pé da capa e aproximam-se na parte superior. Admitamos estar em presença da sequência inicial da adjunção (segundo Houaiss (2001), junção de uma pessoa ou coisa a outra). A grandeza Y, por enquanto, está definida por sua contiguidade posicional. $\mathrm{Na}$ fase seguinte, ela será amalgamada.

Zilberberg (2004. p. 85) define amálgama segundo o Micro-Robert: "mistura de elementos que não combinam bem". Toda a progressividade da adjunção até a liga é passível de ser interrompida na espera de uma resolução. Essa resolução, ${ }^{3}$ denominada liga por Zilberberg, é definida pelo mesmo Micro-Robert como "produto metálico obtido pela incorporação de um ou mais elementos a um metal". De amálgama (progressividade) a liga (fusão), há a incorporação da pluralidade em "um produto".

A fusão, para Zilberberg (2004. p. 79), conta com três fases aspectuais canônicas: fase incoativa, fase progressiva, fase terminativa. São estados aspectuais caracterizados pelas tensões e ambivalências determinados pelos modos de existência peculiares à sintaxe discursiva. Com base em La categoria dei casi, de Hjelmslev (1999), o próprio Zilberberg estabelece duas dimensões que esclarecem a questão do sincretismo: a direção e a intimidade. A primeira opõe aproximação e afastamento entre duas grandezas; a segunda confronta a aderência (o contato) e a inerência (2004. p. 76). Por um lado, a aderência é o contato de uma coisa com outra. Por exemplo, na química, é um processo em que duas substâncias se unem por forças interfaciais. Essa união dá lugar progressivamente à inerência, em que não mais percebemos cada elemento separadamente, pois tais elementos estão atados, fundidos, e não percebemos mais a separação entre eles. Voltemos à capa: na parte superior tal é a fusão que não percebemos que o chão em que cavalga o cavaleiro da cidade antiga é o teto dos automóveis da cidade industrializada.

Vejamos, na figura 1, como se dá a mestiçagem e, logo a seguir, a aplicação desses termos à capa de Luiz Gê:

\footnotetext{
${ }^{2}$ Para Zilberberg (2004. p. 83), a mistura pressupõe a distribuição das grandezas extensivas em classes relativamente estáveis.

${ }^{3}$ Para Hjelmslev (1975, p. 96), o sincretismo pode ser resolúvel ou irresolúvel (na tradução brasileira). Fiorin (2009, p. 26) alerta que esses termos deveriam ser trocados por dissolúvel e indissolúvel, visto que têm o significado de desfazer. Para Zilberberg, no entanto, a resolução é denominada liga, o que nos parece superar essa questão lexical.
}

Disponível em: http://seer.fclar.unesp.br/casa 


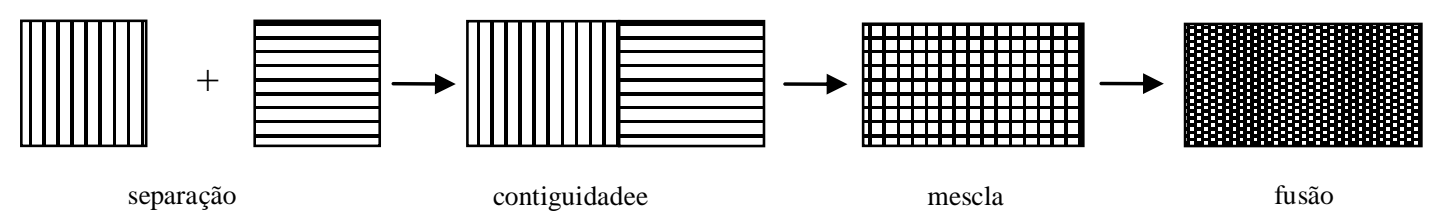

Figura 2: Representação esquemática das dimensões direção e intimidade.

Considerando a terminologia de Zilberberg, temos:

1. separação (ver Gráfico 1): na parte inferior da capa, no plano do conteúdo, embora o teto dos automóveis configure também calçamento, estão ainda separados. Há apenas um processo de adição, isto é, o calçamento da parte inferior, que é formado de tetos de automóveis, tem origem na parte superior da capa, onde é apenas chão em que cavalga o cavaleiro. Em termos tensivos, temos tonicidade elevada (mais... mais...). No plano da expressão, as linhas retas que compõem a figura do calçamento separam-se das linhas retas que compõem a figura dos tetos dos automóveis;

2. contiguidade (incoatividade - adjunção): no plano do conteúdo, há proximidade entre os tetos dos automóveis e o calçamento; no plano da expressão, aproximam-se linhas que compõem a figura dos tetos, bem como a do calçamento: processo de adjunção; nesse caso, temos o começo da aproximação. Tetos de automóveis e calçamento vão, gradativamente, perdendo seus limiares, tensivamente tonicidade elevada em começo de queda (menos do mais);

3. mescla (progressividade - amálgama): "mistura de elementos que não combinam bem". No plano do conteúdo, há tetos de automóveis e calçamento, o que foge ao senso comum de nossa percepção. Há como que uma percepção surreal, visto que chão não pode ser teto de automóvel, e este último não pode ser chão, mas nessa capa é. Susto para o enunciatário, sucesso na manipulação do enunciador, tonicidade ainda elevada (mais do menos), mas já em queda. A transparência da parte inferior da capa vai perdendo espaço para a opacidade, de tal forma que percebemos, pelo olhar, que cores e formas, na expressão, misturam-se.

4. fusão (terminatividade - liga): progressividade interrompida pela resolução. Dá-se, aqui, a mestiçagem, a mistura, de que fala Zilberberg. E temos, para Hjelmslev, superposição de determinadas grandezas, em que uma diferença (a invariante) transforma-se (na condição modificada) numa identidade (a variante). No plano do conteúdo, grandezas como tetos de automóveis e calçamento (figuras discursivas) superpõem-se, e uma diferença (invariante) transforma-se em um espaço aberto, território por onde cavalga o cavaleiro da capa. No plano da expressão, não há nem linhas retas nem formas arredondadas que figurativizam, no conteúdo, pessoas dentro dos automóveis. Ao contrário, linhas retas e formas arredondadas, invariantes, transformam-se em uma identidade variante que, no plano da expressão, é uma superfície reta e lisa e, no do conteúdo, figurativiza o chão em que cavalga o cavaleiro. 


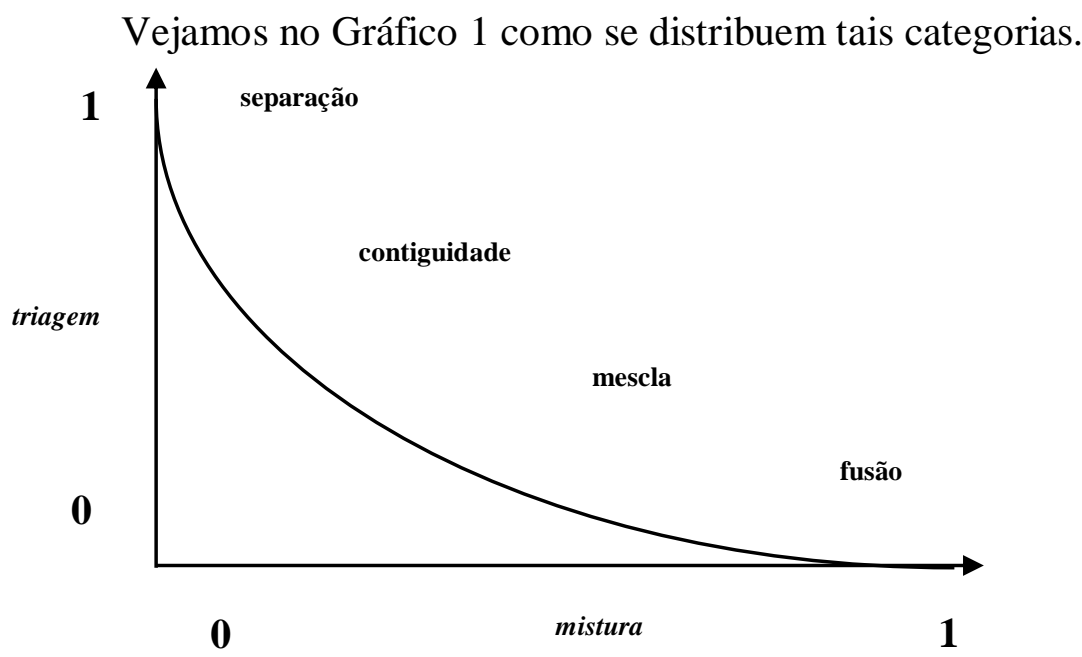

Fonte: Adaptado de Zilberberg (2004. p. 77).

Gráfico 1: correlação entre triagem e mistura.

Zilberberg (2008), no artigo "Causerie sur la sémiotique tensive", faz um estudo da coloração rosa. E afirma: "La complexité de la couleur 'rose' a donc pour résolution le couplage de la 'rougeur' et de la 'pâleur' ". ${ }_{4}^{4}$ Para Zilberberg, com base em Hjelmslev, mistura e triagem são complementares; a primeira como operação de mistura, e a segunda como operação de triagem. A triagem seleciona traços que compõem a mistura. Enquanto o vermelho é consensualmente tido como a cor mais intensa, mais viva, as cores mais pálidas (descoradas) perdem o traço da intensidade, diluem-se, ganham extensidade.

Na capa de Território de bravos, no plano da expressão, enquanto na parte inferior os tons avermelhados e amarelados são intensos (ver Gráfico 2), na parte superior central, esses tons perdem o éclat (vivacidade, intensidade). $\mathrm{O}$ amarelo enfraquece, assemelhando-se ao branco, e o vermelho empalidece e ganha tons de rosa.

No plano do conteúdo, temos, na parte inferior, a área da separação, do bizarro, tetos de automóveis separados do calçamento, enquanto na parte superior central há mestiçagem, chamada por Zilberberg de tédio, tetos de automóveis fundem-se com o calçamento por onde o cavaleiro cavalga em espaço aberto. Veja, no Gráfico 2, a correlação do vívido e do pálido:

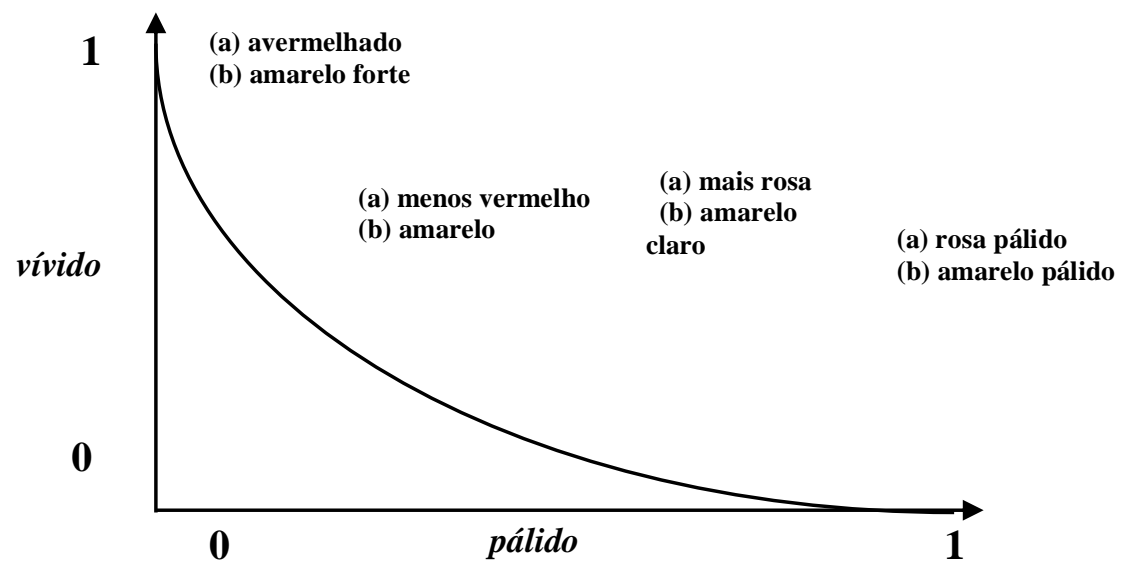

\footnotetext{
4 “'A complexidade da cor 'rosa' tem então por resolução o acoplamento do 'avermelhar' ('enrubescer') e do 'empalidecer'" (tradução nossa). 
Gráfico 2 Correlação do vívido e pálido.

Após as considerações sobre os termos separação, contiguidade, mescla e fusão, faremos, a seguir, uma breve análise do sincretismo na capa de Território de bravos sob o ponto de vista tensivo.

\section{Análise tensiva do sincretismo na capa de Território de bravos}

A escolha do enunciador, na parte inferior da capa, relativamente à tensividade, é pela separação, pelo afastamento entre duas grandezas. No nível discursivo, no plano do conteúdo, tetos de automóveis e calçamento são grandezas separadas; nesse caso, o quantum de afeto é máximo (a intensidade, na separação, é tônica). Utilizando conceitos de processo e sistema de Hjelmslev, na parte inferior da capa, a separação (disjunção) constitui o sistema, as alternâncias (ou...ou), o paradigma. Passando a Zilberberg, verificamos uma posição intermediária do amálgama entre a adjunção e a fusão (liga). No amálgama, há mistura de elementos que "não combinam bem" (parte inferior da capa). A categoria do amálgama revela o estético (ZILBERBERG, 2004. p. 86-87). É a categoria do encontro fortuito, do bizarro, como tetos de automóveis e calçamento, que provoca impacto e espanto. ${ }^{5}$ O bizarro da parte de baixo da capa é constituído, portanto, pelo amálgama, pelo intenso, pelo quantum de afeto máximo (ver Gráfico 3).

Na parte superior da capa, a direção é da aproximação, da mistura, fusão (liga); dilui-se a máxima intensidade, ocorrendo uma difusão extensiva: grandezas superpostas formam a invariante (no plano do conteúdo, território aberto por onde cavalga o cavaleiro). Com a mistura, temos o tédio e a diluição extensiva (ver Gráfico 3).

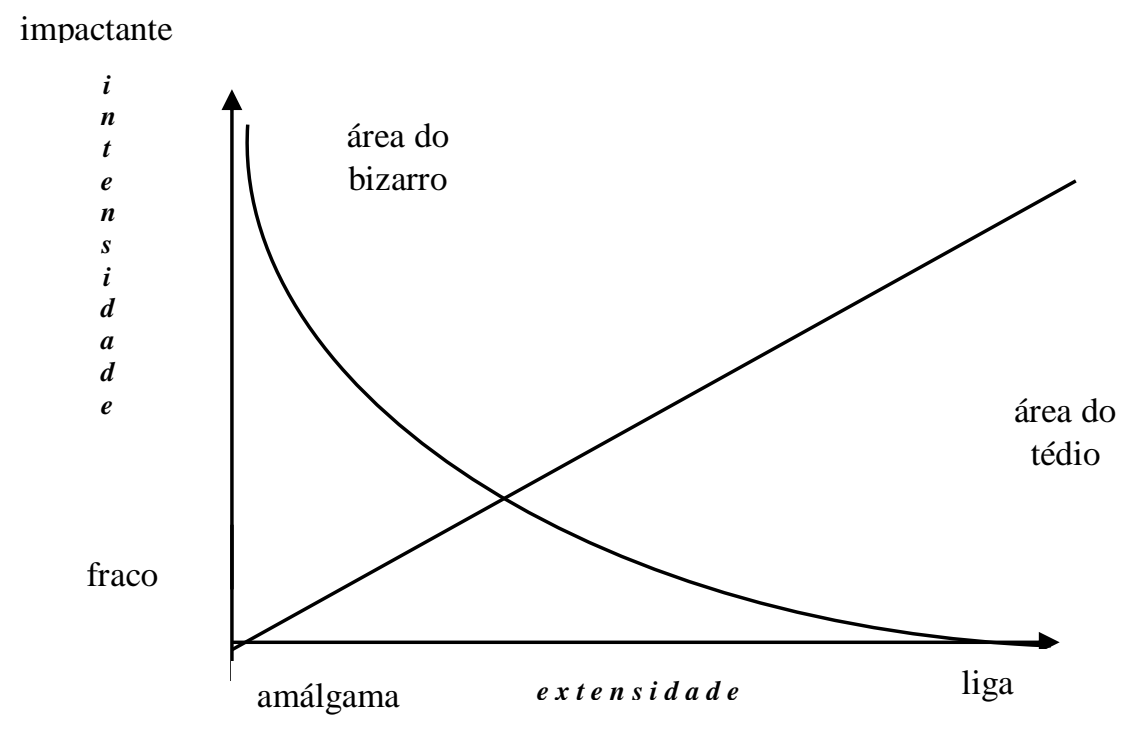

Fonte: Zilberberg (2004. p. 88).

Gráfico 3: Correlação da intensidade e extensidade de tédio e bizarro.

\footnotetext{
${ }^{5}$ Para Greimas, em Da imperfeição, tradução de Ana Claudia de Oliveira. São Paulo: Hacker, 2002. p. 26, “o deslumbramento atinge o sujeito e transforma sua visão: encontramo-nos diante de uma estética do sujeito. Poder-se-ia esperar que o evento estético, que não é senão um 'relâmpago passageiro', se inserisse no discurso da cotidianidade [...]. No entanto, a impossibilidade de dizer diretamente o que se passou, de se dizer enquanto sujeito, o obriga a se debruçar sobre o objeto, separando-se dele depois".
}

Disponível em: http://seer.fclar.unesp.br/casa 
Zilberberg afirma, nesse texto, ser "provável que a mestiçagem seja vista aqui e ali como excessiva, anestesiante, indiferenciadora, o que qualificaria a modalização, a revivescência de certas triagens como desejáveis. [...] a estesia exige o impacto". Considerando o plano do conteúdo, na capa de Luiz Gê, verificamos, na parte superior central, sob o cavalo, a mestiçagem (liga), visto que já não há discretização; ${ }^{6}$ não há alternância do "ou... ou" do paradigma, uma vez que estamos no nível sintagmático. Já não vemos separadamente, polarizados, os elementos tetos de automóveis e calçamento, mas uma figura discursiva apenas: o caminho do cavaleiro da cidade antiga.

Podemos observar na parte inferior da capa de Território de bravos o impacto, o susto da presença bizarra da alternância de figuras, ou... ou... (tetos de automóveis ou calçamento). Na parte superior da capa, a alternância é excluída, cedendo lugar para a coexistência de figuras superpostas, e... e... (tetos de automóveis e calçamento); temos, portanto, o tédio, segundo a terminologia de Zilberberg.

Por um lado, o "ou... ou" do sistema (paradigma) constitui a alternância entre termos eventualmente contíguos; por outro lado, o "e... e" do processo (sintagma) é de coexistência. Ao passar de uma alternância para uma coexistência, há competição entre a virtude conjuntiva do processo e a virtude disjuntiva do sistema.

Do ponto de vista tensivo, a conjunção é apresentada como impossível, pois tetos de automóveis não constituem calçamento; do ponto de vista discursivo, são espécies muito diferentes e distantes para se unirem umas às outras.

É aqui que a estratégia discursiva do enunciador opta pela concessão ("embora seja teto de automóvel, é também calçamento") que intervém, desarrumando o estabelecido e causando o impacto no enunciatário (parte inferior da capa) (Zilberberg, 2004. p. 96-99).

No primeiro contato com a capa de Território de bravos, há um "estranhamento" devido à relação entre as linhas e cores da linguagem visual e os dizeres da linguagem verbal (Luiz Gê, TERRITÓRIO DE BRAVOS). O conceito de estranhamento já era de uso dos formalistas russos. Um artigo de Chklovski intitulado "A arte como procedimento", publicado em Teoria da literatura: formalistas russos, é de 1917. Diz o autor: "E eis que para devolver a sensação de vida, para sentir os objetos [...], existe o que se chama arte. O objetivo da arte é dar a sensação do objeto como visão e não como reconhecimento [...]. O ato de percepção em arte é um fim em si mesmo e deve ser prolongado; a arte é um meio de experimentar o devir do objeto, o que já é 'passado' não importa para a arte [...]" (CHKLOVSKI. In: EIKHENBAUM et al., 1978. p. 45.).

Para Tatit (2010. p. 51), o que importa não é a velha questão da novidade nas artes, mas "a natureza efêmera dessas experiências extraordinárias que jamais deixam de constituir breves escapatórias". Zilberberg (2004, p. 87-88) utiliza a expressão "bizarro", recolhida de Baudelaire, porém com sentido um pouco diferente, para explicitar o Belo: "o 'bizarro', a serviço do impacto e do espanto que o atesta, pode portanto ser descrito em termos de valências tensivas". Considerando os eixos intensidade e extensidade, a categoria do bizarro ocupa a área de máxima intensidade, enquanto o tédio está na máxima extensidade.

Na parte superior até a metade da capa, o enunciador manipula o enunciatário pelo regime do conforto. Desse modo, nada de "estranho", pois o verbal corrobora o visual, mostrando-nos a imagem de um cavaleiro que cavalga em um espaço aberto, naquilo que o

\footnotetext{
${ }^{6}$ Para Greimas e Courtés (Dicionário de semiótica. Tradução de Alceu Dias Lima et al. São Paulo: Cultrix, 1983. p. 124, verbete discreto), "uma unidade discreta caracteriza-se por uma ruptura de continuidade em relação às unidades vizinhas; pode, por isso, servir de elemento constituinte de outras unidades, etc. [...] o conceito de discreção é indispensável para a definição das unidades sintagmáticas, ele não basta para especificar as categorias paradigmáticas que podem ser discretas ou graduadas".
}

Disponível em: http://seer.fclar.unesp.br/casa 
enunciador chamou de TERRITÓRIO DE BRAVOS. Todavia o enunciatário pode assustar-se quando lança o olhar para a parte de baixo da capa, em que o calçamento é constituído pelos tetos dos automóveis. Aqui, temos o regime da afetividade, da intensidade; a dimensão sensível é alta, pois o efeito de sentido é construído com base na surpresa, no susto, no impacto.

Retomando as noções de fratura e de escapatória de Greimas, Tatit (2010. p. 52-53) considera o anseio da ressemantização do cotidiano e a possibilidade de reprogramá-lo para nos favorecer o contato com os acontecimentos estéticos. A condição perfeita do ser seria a união plena entre sujeito e objeto (são de mesma raiz jectus). O sujeito só toma contato com o belo da arte a partir do momento em que seu gosto já estiver integrado ao conceito de belo da comunidade e "promover a transgressão dessa expectativa". Por um lado, o acontecimento extraordinário nega o cotidiano (fratura) e, por outro, ele pressupõe os mesmos programas automatizados da rotina cotidiana, e define-se como escapatória. Portanto, a arte é ao mesmo tempo fratura e escapatória. O que importa não é a questão da novidade (estranhamento) nas artes, mas a natureza efêmera dessas "experiências extraordinárias", pois se constituem em breves escapatórias (TATIT, 2010, p. 52-53). Por exemplo, na fratura, o que o enunciatário percebe como chão de cavalgada passa a ser teto dos automóveis. Para dar-se a escapatória, o sujeito necessita reconhecer que o teto dos automóveis nada mais é do que o espaço onde cavalga o cavaleiro (retomada de programa automatizado da vida cotidiana). Essas duas dimensões (fratura e escapatória) do acontecimento são indissociáveis.

Se pensarmos no ritmo da unidade textual da capa, admitindo para nós ocidentais que o enunciatário começa a observá-la de cima para baixo, temos um ritmo que se acelera na medida em que os olhos do enunciatário correm para o pé da página. A aceleração vai do tédio ao bizarro: o tédio é composto pela área do cavaleiro, enquanto o bizarro o é pela área dos automóveis parados. O susto tem intensidade alta e extensidade reduzida. No plano do conteúdo, o calçamento é também teto de automóvel (bizarro, susto), e ele só é inteligível quando diminui a intensidade e aumenta a extensidade, momento em que o enunciatário se dá conta de que o calçamento em que cavalga o cavaleiro é constituído também por tetos de automóveis.

A fusão das figuras tetos de automóveis e calçamento na parte superior da capa só se dá em relação à separação dessas grandezas na parte inferior da capa. As figuras tetos de automóveis e calçamento do enunciado separam-se na parte inferior e fundem-se na parte superior da capa sob análise. Ora tais figuras, embora pertençam ao espaço, configuram também marcas temporais. Por exemplo, o calçamento em que cavalga o cavaleiro produz o efeito de sentido de uma cidade em seus primórdios. Na base dessa cidade antiga, já estava pressuposto o tempo futuro, em que automóveis tomariam a cidade. Conforme visto no desenho da capa, na área do cavaleiro, reconhecemos a fusão, sincretismo, que se trata de variantes que contraem, em determinadas condições, uma superposição. Nesse caso, o sincretismo é a invariante. Noutros termos, isoladamente, /tetos de automóveis/ e /chão/ são invariantes. Quando, porém, contraem em determinadas condições uma superposição, são variantes. Ora, elas se superpõem na parte superior da capa. Dessa forma, suspende-se a condição de invariante para ter espaço a condição de variantes que, superpostas, contraem sincretismo.

Na capa de Luiz Gê, na parte inferior, não há condição suficiente para a ocorrência do sincretismo, embora possamos reconhecer por pressuposição que o /teto de automóvel/ é calçamento. Na parte superior, todavia, as invariantes /teto de automóvel/ e /chão/ nas condições do enunciado ali presente, ao contraírem uma superposição, são variantes que, superpostas, produzem sincretismo. 
No capítulo 18 de Prolegômenos, em que trata do sincretismo, Hjelmslev (1975, p. 95) afirma que a superposição é "uma mutação suspensa entre dois funtivos, e a categoria estabelecida por uma superposição será (nos dois planos da língua) um sincretismo" (grifo do original). Para o linguista dinamarquês, o sincretismo pode manifestar-se de duas maneiras: por fusão e por implicação (HJELMSLEV, 1975, p. 95). Utilizamos, porém, a terminologia de Zilberberg que inclui, como vimos, separação, contiguidade, mescla e fusão, porque, no estágio atual dos conhecimentos semióticos, consideramos oportuna uma análise tensiva do sincretismo.

Ao utilizar conceitos tensivos de fusão e separação e sua graduação, salta à vista que, no enunciado da capa, tanto no espaço de fusão quanto no espaço de separação, temos:

- No espaço do ator cavaleiro, que é o da fusão, aparentemente livre de antissujeitos, o sujeito cavalga desimpedido, em andamento acelerado. Se considerarmos que a fusão implica a separação do pé da capa, reconhecemos que está latente, sob o espaço tranquilo do cavaleiro, o teto dos automóveis.

- O sincretismo do espaço do cavaleiro já nos predispõe à percepção de que o espaço da cidade moderna é continuação do espaço da cidade antiga. O espaço da modernidade figurativizado pelos carros parados é o espaço da separação de Zilberberg, estágio inicial da fusão, em que notamos a presença de antissujeitos, em andamento lento, um espaço de mais tensões e menos relaxamento. Sob os pés do cavaleiro, espaço da fusão, de relaxamento, já estava previsto o seu antípoda, espaço da tensão, dos antissujeitos, da perda da liberdade.

- O tempo do cavaleiro, vazio de antissujeitos, sem surpresa a esperar, sem tensão, é originante de um tempo, repleto de antissujeitos, com tensão, surpresas, interrupções. Ironicamente o espaço aberto levaria ao tédio. Todavia não é possível um espaço aberto sem considerar o fechamento, como também não é possível considerar o relaxamento da parte superior, desconsiderando a tensão da parte inferior da capa.

Território de bravos é, pois, o tempo e o espaço da convivência de sujeito e antissujeito, de programa e antiprograma, de relaxamento e tensão. Ora, se a capa já nos faz perceber a convivência de contrários, é de pressupor que as sete histórias que compõem o livro também caminharão nessa direção. Luiz Gê supera a visão maniqueísta de repelir posições antagônicas e abre espaço para enunciados dialéticos, em que prevalece a tensividade, a superposição de retenção, relaxamento, contenção, distensão. Espaço, pois, da fusão e da separação ao mesmo tempo: as convergências prevalecem sobre as divergências.

\section{Homologações entre expressão e conteúdo}

conteúdo:

Feita essa análise, podemos fazer algumas homologações entre expressão e

PE : parte de cima da capa :: PC : tédio da cidade antiga (atonicidade) : Liberdade

PE : parte de baixo da capa :: PC: não-tédio da cidade nova (tonicidade) : Não liberdade

Para conquistar as benesses do mundo moderno, o sujeito da cidade perdeu a liberdade no novo espaço industrializado. É um paradoxo. Por meio do automóvel, o sujeito poderia estar em conjunção com a velocidade, a livre circulação; no entanto, no espaço antigo 
do cavaleiro é que se circulava livremente. Verificamos, pela face e pelos gestos dos atores do enunciado da cidade moderna, que eles são portadores das paixões da ira, da irritação. Eles têm automóvel, mas não podem circular. É o contrário do mundo antigo em que o cavaleiro transitava em seu espaço mais tranquilamente. Verificamos, então, que o cavaleiro está solto no espaço, livre, enquanto os passageiros do automóvel estão encurralados e irados dentro de seus veículos. Eles têm uma máquina potente que não pode transitar devido ao engarrafamento.

\section{Conclusão}

Os conceitos de sincretismo de Hjelmslev, de Greimas e Courtés e de Floch podem ser úteis quando se leva em conta uma reflexão dessa problemática teórica. Todavia, para um estudo da teoria, não se pôde deixar de considerar a importância do texto de Zilberberg nos estudos do sincretismo, que se dá gradualmente, tensivamente. Daí a terminologia por ele proposta, que vai da triagem à mistura e da separação à fusão, do bizarro ao tédio. Dentro desse gradiente, temos separação, contiguidade, mescla e fusão.

Todavia, em Luiz Gê, o que verificamos é que o sincretismo, fusão nos termos zilberberguianos, permitiu-nos verificar que o espaço dos enunciados é o espaço tensivo em que contrários e contraditórios convocam-se ininterruptamente.

\section{REFERÊNCIAS}

CAÑIZAL, Eduardo Peñuela; CAETANO, Kati Eliana (Org.). O olhar à deriva: mídia, significação e cultura. São Paulo: Annablume, 2004.

CHKLOVSKI, V. A arte como procedimento. In: EIKHENBAUM et al. Teoria da literatura: formalistas russos. Tradução de Ana Mariza Ribeiro Filipouski et al. Porto Alegre: Globo, 1978. p. 39-56.

EIKHENBAUM et al. Teoria da literatura: formalistas russos. Tradução de Ana Mariza Ribeiro Filipouski et al. Porto Alegre: Globo, 1978.

FIORIN, J. L. Para uma definição das linguagens sincréticas. In: OLIVEIRA, Ana Claudia; TEIXEIRA, Lucia (Org.). Linguagens na comunicação: desenvolvimentos de semiótica sincrética. São Paulo: Estação das Letras e Cores, 2009. p. 38.

FLOCH, J.-M. Verbete "Semiotiche sincretiche". In: GREIMAS, A. J.; COURTÉS, J. C. Semiotica: dizionario ragionato della teoria del linguaggio. A cura di Paolo Fabbri. Milano: Mondadori, 2007. p. 319-320.

GREIMAS, A. J.; COURTÉS, J. Dicionário de semiótica. Tradução de Alceu Dias Lima et al. São Paulo: Cultrix, 1983.

HJELMSLEV, Louis. La categoria dei casi: studio di grammatica generale. Lecce: Argo, 1999.

Prolegômenos a uma teoria da linguagem. São Paulo: Perspectiva, 1975. p. 140.

HOUAISS, Antônio; VILLAR, Mauro Salles. Dicionário Houaiss da língua portuguesa. Rio de Janeiro: Objetiva, 2001. 
CASA, Vol.10 n.1, julho de 2012

OLIVEIRA, Ana Claudia; TEIXEIRA, Lucia (Org.). Linguagens na comunicação: desenvolvimentos de semiótica sincrética. São Paulo: Estação das Letras e Cores, 2009.

TATIT, Luiz. Semiótica à luz de Guimarães Rosa. São Paulo: Ateliê Editorial, 2010.

ZILBERBERG, Claude. As condições semióticas da mestiçagem. Tradução de Ivã Carlos Lopes e Luiz Tatit. In: CAÑIZAL, Eduardo Peñuela; CAETANO, Kati Eliana (Org.). O olhar à deriva: mídia, significação e cultura. São Paulo: Annablume, 2004. p. 69-101.

Causerie sur la sémiotique tensive. (2008). Disponível em: <http://www.fflch.usp.br/dl/semiotica/cursos/zilberberg2008/cz-causerie.pdf>. Acesso em: abr. 2009. 